Ciência e Natura, Santa Maria, v. 37 n. 3 esp. 2015, p. 25-35

Revista do Centro de Ciências Naturais e Exatas - UFSM

ISSN impressa: 0100-8307 ISSN on-line: 2179-460X

\title{
ciênciaenatura
}

\section{Exploring Teachers' Reaction to the Identity Construction of Iranian Students in EFL Context}

\author{
Saeed Ghaniabadi ${ }^{1,}{ }^{*}$, Hamid Reza Hashemi ${ }^{2}$
}

\author{
${ }^{1}$ Assistant professor of Linguistics, Hakim Sabzevari University, Sabzevar, Iran \\ ${ }^{2}$ Ph.D Student of TEFL, Hakim Sabzevari University, Sabzevar, Iran \\ ${ }^{*}$ Corresponding author
}

\begin{abstract}
The substantial achievements of the current research in the field of teaching English as a foreign language highlight the monumental influence of students' identity construction on acquiring a foreign language. Due to the dearth of qualitative research that probe teachers' awareness of the learners' identity construction in classroom-oriented discourse and their reaction to it, the present study is to develop a systematic explanatory theory of those aspects of EFL learners' identity disregarded by teachers in Iranian EFL context. This grounded theory research is founded upon the volunteer and theoretical sampling of 8 under-achieving learners from Azad university of Birjand, Iran. In-depth semi-structural interviews which took three weeks were employed by the researchers. The data collection and analysis procedure occurred between January and February, 2015. The iterative process of analysis yielded teachers' failure to acknowledge the learners' multiple identity as the core category that pulled together three other sub-categories including 1) the ignorance of imaginative identity of the students by teaches 2) teachers' disregard of the multiple and dynamic identity of the learners in educational context 3) teachers' lack of awareness from students contradictory identification with the culture of target language speakers. The results of this study are almost novel and of great significance for Iranian EFL teachers and other practitioners in this field.
\end{abstract}

Keywords: Multiple identities, Cultural identity, EFL context, Identification 


\section{Introduction}

$\mathrm{T}$ he amazing expansion of communication technology coupled with globalization phenomenon has transformed the vast world into the global village. Such an outstanding stride necessitates learning of English as the international language for many communities. In parallel with the growing requirement to English as international language, the field of SLA has also witnessed exponential and multi-dimensional growth in theory and practice to enhance the efficiency of teaching methods and learning theories of language. The field has drawn on a host of disciplines, including psychology, linguistics, sociology, information science and so forth to expand its scope from multiple dimensions. Among the fields emerged from within sociology and post- structural philosophy are the new notions of identity associated with language learning in many aspects. The linkage between identity and second language acquisition was ignored in SLA literature for decades. Proponents of the socio-culturally oriented theories of SLA as Wenger (1998) withheld that factors other than cognitive ones can substantially contribute to a better realization from the mechanism of language learning. It has been shown that, Identity theory as a sub-field of socio-cultural approaches toward language can respond many questions, and remove a wide array of hurdles about the language acquisition process which have for long been detrimental either for language learners or teachers. Such issues have been dismissed by cognitive theorists as periphery and irrelevant to SLA due to their limited scope of learning process for a long time.

Prior to the seminal article by Norton (1995), the relationship between identity and SLA was dedicated to probing issues of macro identity such as cultural identity involving (ethnic identity, linguistic identity, religious identity, etc) with language learning. According to scholars as (Lebov, 1963; Bernestein, 1973) many facets of identity (e.g. cultural identity) are unitary and static in nature. These scholars owed much of their inspiration to a host of modernity and enlightenment philosophers as Kant, Hegel, and Spinoza, Leibnitz who contributed significantly to the introduction of the essentialist nature of human identity. They held that the core of human identity is rationality and reason and confirmed that identity can be analyzed, predicted and conceptualized by drawing on logic and rationality. For these scholars, for instance, when we talk of national identity; its impact on the individuals' language learning would be identical, regardless of whom that individual might be. On the other hand, post-structuraluiasts as (Derrida, 1980; Foucault, 1994; Bakhtin,1981; Hall, 1992 to name afew) posited that these broad and all-inclusive definitions of identity can't capture the intricacies and diversifications among people. Hence, homogenizing people under these broad terms is not a scientific and down-to earth approach from the perspective of poststructuralists. For these thinkers, notions such as ethnicity and national identity have no fixed meaning since they are the product of the complicated inter-relation among historical, socio-cultural, and biological constitutes. Researchers as (Norton, 2000; Wenger 1998; Ueno, 2000; Canagaragah, 1993) withheld that the notion of identity must be approached in a way that take into account the inherent dynamicity, multiplicity and even contradiction of the identity in time and space. They argued that Identity definition must be contextdependent and context-producing in order to explain the heterogeneity within polarized groups in the modern societies. According to these researchers, learners approach language from multiple identity position even at the same time and space. Drawing on this definition from identity, Norton (1995) indicated that the theories of motivation do not justify many aspects of learners' behaviors. She cited many instances of the highly motivated learners that gave up active participation in the class or social context due to the racist, sexist and elitist nature of those environments.

According to Norton $(1995,2001)$, the cognitive theorists of motivation, disregard the fact that affective factors are frequently socially 
constructed in inequitable relations of power between interlocutors and also in higher levels of socio-cultural norms of that context, and are changing over time and space. For Norton, the term identity refers to how a person understands his or her relationship to the world, how that relationship is constructed across time and space, and in what ways a person understands possibilities for future. She went on to say that learners have highly diversified identities. For instance, a learner who acts as a teacher some minutes later, takes the role of a mother then in a different context is identified as an immigrant in language practice throughout the day. This positioning of multiple identities is highly complex and mostly context- dependent. According to Norton in each of the multiple identities that a person posses, they have discrepant thinking orientation. For instance, a person from the position of being a mother may learn English better than the position of being immigrant (a very complex and multi-layered issue).

Generally, adherents of poststructuralists' definition of identity imply that, every time learners speak, they negotiate a sense of self in relation to the larger social world, and recognize that relationship in multiple dimension of their life. So it is not feasible to imagine a fixed identity for a language learner and then predict his behavior based on it. Norton (1995, 2001) made immense contribution to SLA by incorporating this novel conceptualization from identity into language learning experience. To fill this gap in theory, she put forward the concept of investment in language acquisition literature which is in straightforward opposition to the binary terms of motivation theories by Dorney $(1994,1997)$ who categorized learners in binary terms as motivated vs. unmotivated, introverted vs. Extroverted. The notion of investment, according to Norton, signals the socially and historically constructed relationship of the learners to the target language.

Despite the significance of the construct of identity in second language acquisition studies, there is dearth of qualitative studies focusing on the nexus between identity and language learning within the framework of poststructuralists' conceptualization from language. Bearing in mind that identity is not a fixed and coherent trait and quantitative methods are not instrumental in catching its inherent intricacies, qualitative research is the best resort for the analysis of this complicated notion.

To fill this gap, the present research is a modest attempt to probe how learners construct identities in EFL context and how these new identities are neglected by many teachers and consequently impede their optimal learning. This research is built upon the post-structuralists' conceptualization from identity which investigates human agency and subjectivity from a broader scope than the structuralist thinkers.

\section{Literature Review}

\section{Post structuralism and identity}

The concept of the fluid and multiple identities has been widely informed by post-structuralists theories. For Bakhtin (1981, 1984) language is not just a linguistic system of signs and symbols and is not limited to memorizing a set of rules and words to generate language. He confirmed that language consists of others' voices which have been formed to narrate the limitless ranges of events as well as multitude emotions and so forth from the time of its emergence. Thus, when we talk, we draw on others' voice along with our own. Bakhtin (1981) maintained that every word or utterance we generate is a part of a chain constituted from the past history to the present and then the future. In this conceptualization, language is a complex social practice rather than an individualized phenomenon. We can link this idea to identity in the sense that, learners show different reactions (based on their identities) to the voices inherited in the words as well as the discourses of others which constitute the substantial body of language.

Bourdieu $(1977,1984)$ as one of the pioneers of the post-structuralist sociology, argued that in every language practice, there are traces of asymmetric power relation that impedes interlocutors in a discourse from favoring equal rights to speech, due to the biased and partial distribution of power among them. For this reason, the value attributed to speech cannot be understood irrespective of the larger networks of social relationships. In his idea, when a person speaks, he wishes not only to be believed, but also be obeyed and respected. However, speaker's ability to attain respect and recognition 
is unequally distributed, because of the unequal distribution of the symbolic power between interlocutors. To tackle this problem, by means of the introduction of legitimate and illegitimate speaker, he alerts the SLA theorists to regard that the chances of speaking for the learners of a second language are not equally distributed in the sense that some learners have a wider range of opportunity to interact with the target language speakers outside the classroom context and also the teacher in the formal educational context. Hence, it is the responsibility of the teacher to reflect upon the students' different identities and put them in their desirable position, in order to restore equal chances for language practice as much as possible.

It is tangible that in the cognitive theories of SLA, there is no room for taking into account such complex socio- psychological notions, since they regard ESL learners as having a fixed and unitary identity. Weedon (1987) contends that identity of human which she calls subjectivity involves his conscious and unconscious thoughts, his relation to himself and others. She went on to say that for these reasons, identity is historical, social and the sight of struggle.

Post-structuralist approaches to theorizing identity have also been notoriously adopted by cultural theorist Stuart Hall (1992) and post colonial theorist Homi Bhabha (1994) to deconstruct identity categories such as race and ethnicity. In theorizing cultural identity, Hall (1992) confirmed on identity as in process and stressed the significance of the representations following from the discourse constructions from identity. In his notion of new 'identities' Hall provided an alternative theorizing of race that recognizes the experience of race and ethnicity without homogenizing them.

As the result of these conceptualizations from identity, the terms imagined community and imagined identity were among the substantive operational constructs adopted by identity theorists to pin down the polarized aspects of language learning in EFL context including the learners' identity construction and investment in acquiring a second language. For Silberstein (2007), imagined community include affiliation, which extend beyond local and restricted relationships. These imagined communities have profound impact on learner's investment in language learning. This resourceful concept was coined by Anderson (1991) to theorize the relationship between a person and society. He adopted it to indicate that a nation is socially constructed and ultimately imagined by the people who deem themselves as part of that group. It is imagined in the sense that, the member of even the smallest nation will never know most of their fellow members or even hears of them; however, in the mind of each, exist the images of the community to which they have the sense of belonging and affiliation and in cases they are even ready to sacrifice their life for this imaginative community. SLA researchers as (Duff, 2002; Pavlenco, 2007; Kano, 2003, etc) drawing on the concept of imagined community, maintain that communities may be imagined in the sense that language learners have imaginations about their texture and conventions. The term imaginative community is of extensive application in EFL context since learners have no direct contact with target language community and are compelled to have some imagination about them and based on these imaginations have the motivation to learn the new language. Researchers As (Kano\& Norton 2003, Shardakova \& Pavlenco, 2004, Cummins, 1998) maintained that by drawing on the concept of imaginative community, it is feasible to explain that how it is possible that in many cases despite the energetic teachers and the seemingly desirable learning condition, some learners are not ambivalent to learn the new language. They implied that one of the reasons may be the lack of teachers' awareness from the imagined identity of the learners which in many cases is a very complicated notion. Bearing in mind the above-mentioned remarks, we come to conclusion that besides cognitive factors, which incorporate multitude dimensions of mental aspects of learning (memory, explicit and implicit learning, information processing mechanisms, etc), there are also socio-culturally based notions that are widely ignored but remain as indispensible as cognitive elements.

With reference to above-mentioned points, Norton (1997) argued that the lack of learners' involvement in the class room practices might be due to the teachers' failure to acknowledge the learners' identities as immigrants or newcomers to the new country and thus their language needs. 
Along with the principals of poststructuralism, Bashir- Alis' (2006) study slightly provided new insights on L2 identities. Instead of maintaining her L1 identity, Maria, an ESL student went to great length concealing her ethnic identity in the school. She did so by adopting the common linguistic and social traits shared by the dominant African- American social group in the school context. Her eagerness to gain entry into dominant group led her to resist learning standard American English despite its usefulness for her future academic success. Cangajaras (1993) probed US published ESL textbooks used in Sri Lankan classroom that underlined the importance of the text books to language learner identity construction. His study revealed that the dialogues of interlocutors in the text books portrayed racial and gender bias, as well as western middle class values like consumerism, thrift and social mobility. Students, in reaction to the text books adopted a range of reactions including hostility, mockery, and ignorance.

\section{Method}

\subsection{Participants}

The study started with open-ended and semistructured interviews with eight students from Azad university of Birjand, the center of southern Khorasan ,Iran. The identity related issues were the focus of these interviews. In order to improve the validity of the participants' responses, the researchers offered no clue about the type and content of questions to the students before the interview. The participants were categorized as underachieving students since they failed the course general English (the prerequisite for special English) for two times. Their scores were among the bottom 10 percent of the class that included 52 students. Admittedly, it might be the weakness of research in using the scores of examinations as a criterion for selecting the participants in this study; however they are still relevant in the sense that the researcher himself assessed their skills once more to be more confidant of their level of proficiency.

\subsection{Theoretical Sampling}

Rather than statistical sampling which begins with a representative sample of participants, theoretical sampling works by the choice of subsequent subjects based on the information which is emerged from the data already coded. More specifically, instead of statistical sampling of participants to make sure that each member of the accessible population has a chance of being selected, this study adopted theoretical sampling to direct the questions applied to collect the sources of data in order to ensure that theory could be developed fully. Participants were sampled by their willingness to express their views and experience of identity issues to the researcher. The theoretical sampling of concepts ended after interviewing three participants since the researcher experienced theoretical saturation.

\subsection{Data Analysis}

Grounded research involves a constant comparative methodology that combines data analysis with the data collection and the central concern of data analysis in grounded theory is built upon three types of coding procedure : open, axial and selective (Glaser\& Strauss, 1967; Strauss \& Corbin, 1998).

\subsection{Interview}

Grounded theory has the specific goal of exploring students' experiments and placing them in. Referring to Sideman (1991) the interviews were designed to acquaint the participants with the nature of study, to establish rapport, to provide a context for phenomenon, and then to attain the depth and details of the experience. Interviews were continued until redundancy was reached. Interviews were held in Persian due to the limited proficiency of the participants and then transcribed and translated into English to vividly represent the dynamic nature of the performed conversation. Each of the transcriptions was returned to the participants for their review so they can remark on the accuracy of the document. During the research each student was assured the confidentiality through the use of pseudonyms in the reporting of the data.

\subsection{Open Coding}


Open coding takes place at the outset of the study. The principal goals of open coding are to conceptualize and categorize data, gained through two main analytic procedures: making comparisons and asking questions of the data. Open coding began with the labeling of many individual phenomena. In this time, a number of individually labeled concepts are gathered to form a more authentic and abstract categories. Once categories are shaped in open coding, they are classified in terms of their properties and dimensions. As (Strauss \& Corbin, 1998) indicate, open coding is achieved by examining the transcripts line by line, sentence by sentence , and some time, by examining document.

\subsection{Axial coding}

The second stage of data analysis is axial coding. Strauss and Corbin (1998) define axial coding as the process of relating categories to their sub-categories and linking a category at the level of property and dimensions. In axial coding, four analytical processes are occurring a) continually relating subcategories to category $b$ ) comparing categories to collected data c) expanding density of the categories by detailing their properties and dimensions, and (d) exploring variations in the phenomena.

\subsection{Selective Coding}

The final stage of data analysis in grounded theory is selective coding, which is founded upon the open and axial coding. Selective coding is the process of the central or core category; systematically linking it to other categories; validating those relationships and filling the categories that need further refinement and development. (Merriam, 2002: Strauss and Corbin, 1998) stated this central or core category should have the analytic power to pull the other categories together to form an explanatory whole.

\section{Limitation of the Research}

Despite the participant's validation of the emerged concepts and categories and my attempt to triangulate the data against official documents, readers should proceed with caution as they read the findings. Qualitative researchers are the instruments for gathering data and as human beings they bring with them, their own constructions of the world. However, rigorous analytic scheme of grounded theory helped me ground the findings in the data and avoid bias.

\section{Results and Disscusion}

Drawing on the constant comparative technique, the theoretical sampling and analytic procedures yielded teachers failure to acknowledge different aspects of learner's identities as the core theoretical category which pulled together three other categories. These categories include 1) teachers' ignorance of imaginative community and imaginative identity of the learners 2) ignorance of the multiple, dynamic and contradictory identity of the students by teachers 3) teachers' lack of awareness from students' contradictory identification with the culture of target language speakers ignorance of the target speakers. With respect to the first category, the results of interviews indicated that some participants' conception from the target language community was not positive from many aspects. They were also incapable of constructing ideal and desirable identity in regard to the imagined target community to facilitate their better linguistic performance in wider context. Their remarks indicated that they were not able to define for themselves an imaginative identity in their EFL context for creating attachment with the target language community. For these learners, there was no ambivalence for becoming engaged with the communities of the target language (e.g., USA, Britain, Canada, and Australia). This as Norton (1995) implied led to their lack of investment in the target language.

The second category referred to the ignorance of the multiple and dynamic identity of the learners by teachers. Some participants complained that their previous language teachers behaved them as if they were kids. One of the participants maintained that the whole class time was devoted to few top students whom they believed to have gone to supplementary classes and they did not receive enough attention $n$ the part of the EFL teacher. For example, one of the interviewees expressed his strong disapproval from his teacher, while 
instructor in wanted him to read the texts in front of the class and then criticize him sharply when he couldn't read the text well. This behavior positioned the learner as a person with an inferior and degraded identity in relation to English language.

With respect to the third category, participants argued that the respected teachers either in high schools and university, most of the time talks about grammar and vocabularies. Given the fact that the language is not limited to mere linguistic aspects, they criticized sharply of their lack of knowledge about the culture of the target language speakers.

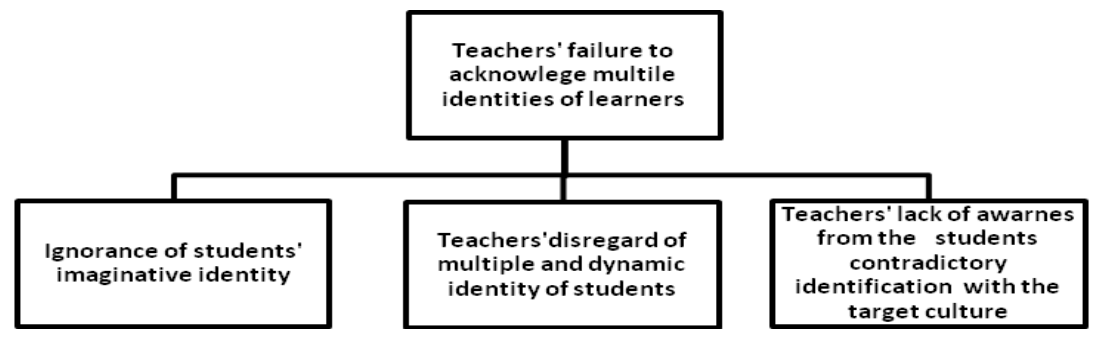

Diagram 1: Diagram related to the core catregory and the three sub-categories

\section{Ignorance of the students' Imaginative identity}

One of the main characteristics of EFL context is that learners have very limited opportunity to interact with the native speakers and also limited chance to make acquaintance with the multiple dimensions of the target language culture. In such conditions, the term imagined community coined by Anderson (1991) can describe vividly how EFL learners can create many aspects of the target culture through their imaginative power and establish bonds and affiliations with those speakers in their world of fantasy. If the learners' imagination toward the culture of the target community is not positive and bears negative aspects, it hinders their success in learning perfect English. Because as Norton (2001) implied, they do not invest in the practices of the target language. To have a profound understanding of this complicated issue the researchers cite the attitude of one of the participants:

To be honest, I am not interested in the culture of American people. They have too many problems. Every day we hear news of inflation, joblessness and corruption and killings in their country. In my idea, they just claim that they are prosperous but in my idea there is no real dignity and happiness for them. Off course, I know that English is the international language; this is not enough because I don't respect its native speakers, and I don't know why many
Iranians are in love with the corrupted culture of English speaking countries.

Regarding the attitude of this participant toward the target language community, we realize that he takes an identity position that prevents his investment in the practices of the target culture. This negative and rather hostile realization from western culture brings generates an undesirable and hostile imaginative identity for learning English, despite knowing the fact that English is the international language. To put more simply, this imagined identity blocks his investment in English language. Another participant said:

Whenever I think about Europe and United States I feel useless and experience a sense of painfull humiliation. Although, I haven't traveled to these countries, I have noticed in movies and those visited US and Europe that how developed they are. How can I imagine myself successful in these countries while the most talented and richest people of the world migrate there to find a job and sometimes low level jobs? I think neither USA nor Europe needs people like me. Off course, I prefer to live in my own country rather than living as a degraded person in western countries. For this reason, I am not so motivated for learning English. I am just forced to learn it to pass the exam.

With reference to the remarks of this participant, we come to realize that he hasn't taken a fierce position to the target community of native speakers of English. The imaginative 
community that this and many participants have at their disposal, turns into a hurdle for their language learning ambitions. Such feeling of inferiority toward the imagined community led them to construct their identity in undesirable way as a humiliated and degraded learner. In such cases, this participants' imaginative community positioned him in the state of dominated entity; consequently this type of identity construction has adverse influence on the process of language acquisition.

\section{Ignorance of the multiple identities of learners}

Issues pertinent to affective factors have been taken into account by a host of SLA theorists, however as (Toohey, 2000; Cummins, 2006; Kanno, 2008) implied, the problem was the ignorance of the extremely complex nature of the learners' feelings and motivation in learning language in EFL or ESL context in relation to the wider socio-economic context and the delicate power relationship defined as the capillaries of power in Foucaultian term. While scholars as Krashen (1985) treated affective factors as crucial issues for acquiring new language, he widely neglected the fact that these affective factors are socially, historically and culturally constructed, in the sense that learners' identity is multiple, multilayered and in the state of flux. The experience of the participant in this study also accounted for the fact that teachers widely dismissed this crucial aspect of the learners' subjectivity and agency in their teaching practices that in turn leads to the nonparticipation and lack of investment in the language practices despite the notable motivation of students. Regarding this issue, another participant withheld that:

I never forget the second session of my general English class. In the prior session, the instructor wanted us to read the text fluently and translate it into Persian. I practiced a lot for that. When I volunteered to read the text, he asked me to read it in front of the class. This was the most terrible event in my university days, because I felt as if I was a first grade student of primary school. I had to stand in front of the classmates that were much younger than me. The tragedy was the time that I was stuttering during my presentation, since then, I had a mixed feeling of anger and stress toward both the teacher and the course.
The bitter experience of this learner is illuminative in showing that while, initially he was a highly motivated student, but due his undesirable experience he did not invest in the class practices. When he wanted to talk in front of the class, he felt that he has been positioned in the low and derogatory state and his social identity as a guidance school teacher was interrogated and somehow under-represented by the instructor. This participant had multiple identities as a father, guidance school teacher, and student. According to this participant, the teacher positioned him as a student of primary school by asking him to come in front of other students to read the text, for this reason he felt the lack of respect from the teacher's and despite being highly motivated had weak performance in class.

There are many similar instances in Iranian EFL classes either in institutes or official context. Numerous teachers largely ignore the multiple identity position of their students by just considering them as students. They are not aware of the fact that students can perform better in other social identity position. Another participant shared his experience with the researcher and said:

My instructor in the general English course always gives us a lengthy list of words to remember and many grammatical exercises to do. Most of the time, he talks about the importance of English for passing MA and also TOEFL. Although he works very hard and many students admire his knowledge and effort, I get tired and feel bored in his classes to such extent that I grow to hate grammar. If I dared, I would tell him that I don't want to pass MA or become instructor in university, I just want to be able to understand English songs and movies. Because the words used in which are very different from what I learned in this class. If, in every session he wrote us a few popular songs on a whiteboard or at least some related words for them, I would learn hundreds of new words and could even memorize my desirable English songs. In this way, I would learn English much better.

Considering the aforementioned class, the teacher has envisaged the identity position for the learners as MA students for their future. He has extensively failed to acknowledge that his learners have other identities that are not in accordance with the language practices offered and orchestrated in the educational context. In 
the above remarks, the student has chosen to construct his identity in relation to English, just as an ordinary person who likes to watch movies or listen to music. For this learner, the academic identity envisaged for him by the instructor has no priority and is of no interest in the given space or time. There are many similar instances in such conditions in our teaching context wherein EFL teachers stick to restricted aspects of the learners' identity position and based on this narrow realization, implement their teaching trajectories. In such instances, as Norton (2001) implies, highly motivated students do not invest in the language practices offered by teachers and many learners abandon their active participation in class.

\section{Teachers' disregarding of the student's contradictory identification with the culture of target language}

It goes without saying that language and culture are inextricably intertwined phenomena from multiple perspectives. As Bakktin (1981, 1984) implied, language is not just a set of grammatical rules and mass of vocabularies, but it is the world of others' voices from the past until now and even future. Albertini (1993) implies that a language mirrors the cultural practices of those speakers. In vygotskian orientation, language is a cultural artifact which grows in the realm of the socio-cultural context. Despite the immense role of culture in language learning, the findings of this research indicate that it has been widely ignored in the class environment and in the EFL text- books. The importance of EFL student's awareness of the cultural identity of target language is crucial since they have very limited accesses to the native speakers of that language. Therefore most have problems in relation to socio-linguistic, pragmatic and illocutionary competence. Regarding this problem one of the participants said:

"I and most of my classmates are curious to know the lifestyle of native speakers and also their customs and traditions. But when I open the text book, I can hardly find information about these issues. Most of the texts give information about topics that we already know. Topics encompassing air pollution, importance of technology, and the events that happen between Iranian interlocutors. In my idea, if there were more interesting topics about the way of life of native speakers, for instance their famous actors, their marriage ceremony or their foods and even the problems that they have in their societies, we would be more enthusiastic about learning English. I am a teacher and understand these things well. You just need to open the English text books and look at the pictures none of the people in these pictures are even similar to the culture of target language. My feeling of these books is that I'm studying texts that have been translated from Persian into English. Even the characters in the book are like robots without creativity and enthusiasm talking about tedious topics."

These talks on the part of a participant are very familiar for most of the Iranian English teachers and professionals in the field of ELT. Routine topics in the EFL text- books as well as the books compiled for general English in university are not in accordance with the scientific achievements of SLA theorists in these decades. Ignorance of the cultural identity textually and even visually causes the learners to learn the limited language skills like translation, grammar. These learners encounter many problems when they intend to interact with native speakers. The tragedy is that most of them don't know how to start and close conversation, how to utter requests or apologies and even how to ask for help in informal context. They are not aware of the most fundamental conventions of dealing in ESL context. These problems arise due to the lack of attention to and awareness of the cultural identity of target language speakers which is best manifested in their ordinary life, in EFL books and by teachers.

Another participant shared his view on this issue by adding that:

"Sometimes I feel that my teachers don't have the least information about the cultural norms and tradition of English speaking countries. Because they rarely talk about them. I just remember that in one occasion, our instructor talked about cultural differences between Iranian and American in inviting guests and serving food. I guess every one enjoyed it because some aspects of their culture were funny and somehow surprising for us. Except that time, he and my previous English teachers are sticking to the contents of books. If you have look at our text book you notice there is no exciting conversation. I feel the texts are artificial talking about the events that never touch our sense of curiosity. I'm sure my classmates 
share these ideas with me. Maybe teachers are afraid of talking about these issues due to some problems related to sociopolitical condition in Iran to hold their position."

One of the principal shortcomings of Iranian teachers and even university instructors is their limited access to native speakers of English. Being under economic burden, they have limited access to countries like England, Britain and US, in order to experience and evaluate their knowledge of the cultural identity of the native speakers. It must be noted that the teachers' negligence of different aspects of the target culture makes the content knowledge transferred by teachers not fostering their tendency for learning a foreign language. To put another way, increasing political tensions between Iran and these countries has made it even more cumbersome to establish relations and gain know knowledge of the culture of the native speakers. Referring to the participants' accounts from their experience, it could be inferred that their books do not include sufficient identity choices for the learners.

\section{Conclusion}

The results of this grounded research by drawing on the many pages of transcribed data, shed light on some aspects of language teaching profession that are mostly disregarded in Iranian EFL context. This study revealed that EFL learners have imaginations of the target language community and based on these imaginations adopt an identity position to interact with it. According to this study, most teachers are not aware of this notion or if they know about it, they do not sufficiently try to improve the sense of affiliation of the learners to the target community through wide spectrum of the available facilities. It is explicit and outspoken that if EFL teachers understand the imaginative identity constructed by learners, their efficiency would be doubled.

Adoption of multiple identities by learners in educational context as the logical consequence of poststructuralists and identity theorists is another under research topic which is of indispensible value from many facets. This study indicated that the negligence of the multiple identities of learners can have disastrous consequences for them. Teachers must be aware that their students are not just the passive recipient of the knowledge transferred by them. Every time learners speak they negotiate a sense of self in relation to the larger context which may include the norms of the society. A learner in the class at the same time may be a son, student, member of a team, employee and so forth. It is the job of teacher to become aware of these multiple identity positions and help learners do practice language with respect to their desirable identity position.

It was also shown that the cultural identity of the target language speakers is ignored in the educational context either by teachers or in textbooks. Most teachers are not aware of many aspects of this type of identity due to lack of chance for real life interaction with native speakers. As noted in the preceding section, Language is not just the strings of words and grammatical rules. It also encompasses sociolinguistic, pragmatic and discourse competence as its building blocks. The tragedy is that these notorious concepts are widely neglected in Iranian EFL context. The results of this research, if applied can dramatically enhance the quality of teachers' management of their English classes and also broaden the language knowledge of their students in the best possible way.

\section{References}

Albertini, J. (1993) Critical literacy, whole language, and the teaching of writing to deaf students: Who should dictate to whom? TESOL Quarterly, 27(2), 59-73. Anderson, B. (1991). Imagined communities: Reflections on the origin and spread of nationalism (Rev. ed) New york: Verso.

Bakhtin, M. (1981). The dialogic imagination: Four essays by M.M. Bakhtin. Austin, TX: University of Minosota Press.

Bakhtin, M. (1984). Problems of Dosoveskysm Poetics (C. Emerson, Trans.). Minneapolis. M N: University of Minnesota Press.

Bashir-Ali, K. (2006). Language learning and definition of one's social, cultural and racial identity. TESOL Quarterly, 40(2), 628-639.

Bahabha, H.K. (1994). The location of culture. London\& New York: Rutledge. 
Bernestine, B. ed. (1973) Class, codes and control, volume (2): Empirical studies. London: Rutledge\& Kegane.

Bourdieu, P. (1977). The economics of linguistic exchanges. Social Science Information, 16(6), 645-668.

Bourdieu, P. (1984). Distinction: A Social Critique of the judgment of taste (R. Nice, Trans). London: Routledge \& Kegan Pou.

Canagrajah, S. (1993). American text- books and Tamil students. Discerning Ideological tensions in the ESL classrooms. Journal of Language, Culture and Curriculum, 6(1), 143156.

Derrida, J. (1980). Writing and difference. Chicago, IL: University of Chicago Press.

Foucault, M. (1994). The order of things: An Archeology of the human science. USA: Vintage.

Hall, s. (1992). The question of cultural identity. In S. Hall, D. Held \& T. McGraw (Eds), Modernity and its future (pp. 273-316). Cambridge, Polity Press

Heller, M. (2007). Linguistic minorities and modernity: A sociolinguistic ethnography. London: Continuum.

Cummins, J. (2000). Language, Power and Pedagogy: Bilingual children in the Crossfire. Clerdon: Multilingual Matters.

Kanno, Y. (2003). Negotiating bilingual and bicultural identities: Japanese returnees between two worlds. Mahwah, NJ: Erlbaum.

Dorney, Z. (1994). Motivation and motivating in the foreign language classroom. Modern Language Journal, 81 (4), 482-493.

Dorney, Z. (1997).psychological process in comparative language learning: Group dynamics and motivation. Modern Language Journal, 84 (4), 185- 198.

Duff, P.A. (2002). The discourse co-construction' of knowledge, identity, and difference: ethnography of communication in the high school mainstream.

Glaser, B., \& Struss, A. (1967). The discovery of grounded theory: Strategies for qualitative research. Chicago: Aldine.
Hall, S. (1992) The question of cultural identity. In S. Hall, D. Held \& T. McGraw (Eds), Modernity and its future pp. 273-316. Cambridge: Polity Press.

Kano, Y\& Norton, B. (eds) (2003). Imagined communities and educational possibilities. Journal of Language, Identity and Education, 2(4) pp.34-58.

Krashen, S. D. (1985). The Input hypothesis: Issues and Implications. Harlow: Longman.

McKay, S. L., \& Wong, S. c. (1996). Multiple discourse, multiple identities. Investment and agency in second language learning among Chinease immigrant students. Harward educational.

Merriam, S. B. (2002). Introduction to qualitative research. (Eds), Sanfransisco, CA: Jossy-Bass.

Miller, J. (2003). Audible difference: ESL and social identity in schools. Clevdon: Multilingual Matters.

Norton Pierce, B. (1995). Social Identity, investment, and language Learning. TESOL Quarterly, 29(1), 9- 31.

Norton, B. (2000). Identity and language learning: gender, ethnicity and educational change. Harlow: Pearson Education.

Norton, B. (2001). Language, identity, and the ownership of English. TESOL Quarterly, 35 (2), 409- 429.

Sharadakova, M., \& Pavlenco, A. (2004). Identity options in Russian Textbooks. Journal of Language, Culture and Curriculum, 6, 143156.

Stauss, A., \& Corbin, J. (1998). Basics of qualitative research: Techniques and Procedures for developing grounded theory. Thousand Oaks, CA: Sage.

Uno, J. (2001). Detraditionalization: Japanese students in the USA. Language, Culture, and Curriculum, 14, 76- 89.

Weedon,C.(1987). Feminist Practice: Learning, meaning, and identity. Cambridge: Cambridge University Press.

Wenger, E. (1998). Communities of Practice: Cambridge University Press. 